


\section{Deutiche Reichä u. Preuptiche Oejeke}

Die Guttentagide Gammlung von Textausigaben mit Inmerfungen im Tajdenformat entbalt

in mebr als 230 Bänden alle wid)= tigeren Befeze in unbedingt zuberláffigem Ubdruat und muftergültiger

Erläuterung

$+$

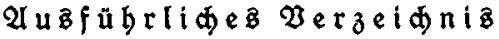

befindet fid binter dem Gadregifter 


\title{
Suttentagide $\widehat{S} \mathfrak{a m m} \mathfrak{m} \mathfrak{m}$ 2Tr. 63

\section{Die \\ $\mathfrak{P r e u p i i j h e n ~} \mathfrak{d} \mathfrak{a g d g e j e k e}$ \\ in ifrer geltenden $\mathscr{F a f j u n g}$}

Wit Er $\mathfrak{d a ̈ u t e r u n g e n ~ v e r f e b e n ~}$

\author{
bon \\ Y. $\mathfrak{B}$ orn \\ Crfter Bargermeifter i. R.
}

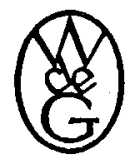

Berlin und Beipzig 1928

WaIter Se Srunter \& E.

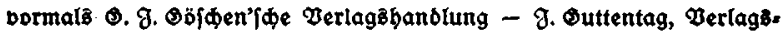
buфbandlung - Beorg Reimer - Garl $\mathfrak{g}$. Träbner - Beit \& Eomp. 
